\title{
Auditory brainstem response patterns in patients of diabetes mellitus: A hospital based study in Punjab
}

\author{
Jaspreet Takkar', Babita Bansal'2, Gagandeep Singh Grover ${ }^{3}$, K.C. Manchanda ${ }^{4}$ \\ ${ }^{1}$ Assistant Professor, Department of Physiology, Gian Sagar Medical College \& Hospital, Ramnagar, Patiala, Punjab, India, ${ }^{2}$ Ph.D Scholar \\ (Med. Physiology), Department of Physiology, Gian Sagar Medical College \& Hospital under Baba Farid University of Health Sciences, \\ Faridkot, Punjab, India, ${ }^{3}$ Social \& Preventive Medicine, State Epidemiologist, Punjab, India, ${ }^{4}$ Principal, Chintpurni Medical College, Pathankot, \\ Punjab, India
}

\section{A B S T R A C T}

Background: Diabetes Mellitus is an important health issue throughout the world. It is a common endocrine and metabolic disorder. Neuropathy is the most precocious and frequent late complication of diabetes mellitus. Evoked potentials offer the possibility to perform a functional evaluation of neural pathways in the central nervous system. Aims and Objectives: This study is a modest attempt to find the relationship of central diabetic neuropathy with the disease, if any, by evaluating the brainstem auditory evoked potentials. Materials and Methods: Brainstem auditory evoked potentials were recorded in type-2 diabetic patients taken from OPD of Medicine department of Guru Nanak Dev Hospital, Amritsar. Patients were divided into three groups based upon the duration of disease. The parameters recorded were absolute latencies of waves I, III and V \& Inter-peak latencies (IPL) I-III, I-V, III-V. Results: The results showed no statistically significant changes in any of the above parameters. Discussion: This could be attributed to fairly good glycemic control of the patients included in the study. Thus, we conclude that patients with good glycemic control develop no auditory peripheral or central diabetic neuropathy irrespective of the duration of disease. However this study has its own limitations and further research is required to substantiate these results.

Key words: Type-2 diabetes Mellitus, IPL, BAEP, Absolute latencies
Access this article online Website:

http://nepjol.info/index.php/AJMS DOI: 10.3126/ajms.v6i3.10974

\section{INTRODUCTION}

Diabetes Mellitus is an important health issue throughout the world. It is a common endocrine and metabolic disorder. The World Health Organization estimates that more than 180 million people worldwide had diabetes in 2005. This number is likely to more than double by 2030. ${ }^{1}$ Type 2 diabetes mellitus is increasingly common, primarily because of increase in prevalence of a sedentary life style and obesity. ${ }^{2}$ Neuropathy is the most precocious and frequent late complication of diabetes mellitus. So far most of the clinical and diagnostic studies on diabetic neuropathy have been concerned only with peripheral and autonomic nerves but recently with the refinement of evoked potential techniques detailed exploration of sensory pathways in central nervous system has been possible. ${ }^{3}$
The ABR (Auditory Brainstem Response) test is a measure of neural synchrony of the auditory nerve through the auditory brainstem structures. ${ }^{4}$ Evoked potentials are electric signals from the central nervous system triggered in response to the stimulation of a receptor. These tests are characterized by very high sensitivity, although not specificity, they are non-invasive and have no side effects. A nerve tract damage increases the latency and reduces the amplitude of the response. Evoked potentials offer the possibility to perform a functional evaluation of neural pathways in the central nervous system. They are extremely useful in clinical practice, as it is possible to ascribe changes in the wave latencies to specific anatomic structures in the central nervous system. ${ }^{5}$

Various studies have reported contradictory results regarding the involvement of auditory pathways in

Address for Correspondence:

Ms. Babita Bansal, MSc.(Med. Physiology), Ph.D Scholar, Department of Physiology, Gian Sagar Medical College \& Hospital,

Ramnagar, Rajpura, Patiala, Punjab, India.

E-mail: babitanvi@gmail.com; Telephone no. +919023860042

(C) Copyright AJMS 
patients of diabetes mellitus. Therefore, this study is a modest attempt to find the relationship of central diabetic neuropathy with the disease, if any.

\section{MATERIAL AND METHODS}

The diabetic patients were taken from the OPD of Medicine department of Guru Nanak Dev Hospital, Amritsar. Patients who had no subjective symptoms of hearing loss and had normal hearing tests (Weber's and Rinne's) were selected for the study. BAEPs were conducted on an outpatient basis after getting a written and informed consent from patients. BAEPs were tested in the department of Physiology, Government Medical College, Amritsar using RMS EMG EP Mark II version: 7.5.7, 2 Channel (PC based) machine, manufactured in India.

Brainstem Auditory Evoked Potentials (BAEPs) were recorded in three groups of 30 subjects each. The groups were divided as:

Group I: $\quad 30$ Type-2 diabetic patients with duration of the disease $<5$ years

Group II: 30 Type- 2 diabetic patients with duration of the disease 5-10 years

Group III: 30 Type-2 diabetic patients with duration of the disease $>10$ years.

Fasting blood sugar levels of all the subjects in all the three groups were recorded and mean fasting blood sugar level of each group was calculated.

The hearing threshold of the patients was done and the stimulus was delivered at $60 \mathrm{~dB}$ higher than the hearing threshold. The stimulus used was a brief click which was a square wave pulse of 0.1 milli second duration. The clicks were delivered through earphones. A click rate of $11.1 \mathrm{~Hz}$ was used. 2000 clicks were delivered to both the ears and the average of them was accepted as BAEP response. The stimuli were picked by the surface electrodes and a recording in the form of wave $I-V$ was obtained on the screen on being averaged, filtered and amplified by the machine. The machine has an in built muscle artifact rejecting facility. The low filter was set at $100 \mathrm{~Hz}$ and high filter at $3000 \mathrm{~Hz}$.Minimum three readings were obtained in each patient to ensure reproducibility.

The following parameters were measured for the analysis of BAEP:

(i) Absolute latency of waves I, III, V

(ii) Interpeak Latency of I-III, I-V, III-V.

The results obtained were analyzed by one way Anova test to study the mean, standard deviation and standard error.
Also, advanced Post Hoc Tukey HSD test was applied to study the difference of means of the values obtained and to study the correlation of the data obtained for different study groups.

\section{RESULTS}

Table 1 and 2 show the age and sex distribution of cases respectively.

Table 3 shows the comparison of group I \& II with respect to latencies of wave I, III \& V; IPL I-III, I-V, III-V. The results show statistically insignificant variation in all of these parameters in both the groups.

Table 4 shows the comparison of group I \& III with respect to latencies of wave I, III \& V; IPL I-III, I-V, III-V.The results show statistically insignificant variation in all of these parameters in these groups also.

Table 5 shows the comparison of group II \& III with respect to latencies of wave I, III \& V; IPL I-III, I-V, III-V. There is no statistically significant change in any of these parameters in these groups.

\section{DISCUSSION}

The peripheral and autonomic neuropathy occurring in diabetic patients is well known. Whether there is also a specific central nervous system involvement has not been well documented. It is reasonable to ask whether such a ubiquitous metabolic derangement and diffuse angiopathy might involve any part of the nervous system. ${ }^{6}$

A team of researchers concluded from pathological material that diabetic neuropathy is a disease of peripheral nerves and that degeneration in the CNS is unimportant. ${ }^{7}$ Major textbooks on diabetes either disregard cerebral involvement or minimize its existence. ${ }^{6}$ Similar results have been found in the present study. Our findings showed no statistical significant variations in the absolute latencies of wave III

\begin{tabular}{lccc}
\multicolumn{4}{l}{ Table 1: Sex wise distribution of cases } \\
\hline Category & Male & Female & Total \\
\hline Group I & 14 & 16 & 30 \\
Group II & 14 & 16 & 30 \\
Group III & 17 & 13 & 30 \\
\hline
\end{tabular}

\begin{tabular}{lcccccc} 
Table 2: Age wise distribution of cases \\
\hline Category & $\mathbf{3 0 - 4 0}$ & $\mathbf{4 0 - 5 0}$ & $\mathbf{5 0 - 6 0}$ & $\mathbf{6 0 - 7 0}$ & $\mathbf{> 7 0}$ & Total \\
\hline Group I & 1 & 11 & 14 & 4 & 0 & 30 \\
Group II & 0 & 2 & 18 & 10 & 0 & 30 \\
Group III & 0 & 0 & 8 & 16 & 6 & 30 \\
\hline
\end{tabular}




\begin{tabular}{lcccc} 
Table 3: Comparison of Group II (DM 5-10 years) with Group I (DM<5 years) & \\
\hline Parameters & $\begin{array}{c}\text { Mean } \pm \text { SD } \\
\text { Group I (DM<5 years) }\end{array}$ & $\begin{array}{c}\text { Mean } \pm \text { SD } \\
\text { Group II (DM 5-10 years) }\end{array}$ & P value & \\
\hline Wave I (latency) & $1.7413 \pm 0.2080$ & $1.7430 \pm 0.2438$ & 1.000 & NS \\
Wave III (latency) & $3.6977 \pm 0.2061$ & $3.6690 \pm 0.2121$ & 0.960 & NS \\
Wave V (latency) & $5.6107 \pm 0.3006$ & $5.7133 \pm 0.2804$ & 0.618 & NS \\
Inter peak latency I-III & $1.9563 \pm 0.2394$ & $1.9260 \pm 0.3119$ & 0.975 & NS \\
Inter peak latency I-V & $3.0607 \pm 0.3220$ & $3.0620 \pm 0.3423$ & 1.000 & NS \\
Inter peak latency III-V & $1.9130 \pm 0.3545$ & $2.0443 \pm 0.3501$ & 0.609 & NS \\
\hline
\end{tabular}

\begin{tabular}{lcccc} 
Table 4: Comparison of Group III (DM>10 years) with Group I (DM<5 years) & \\
\hline Parameters & $\begin{array}{c}\text { Mean } \pm \text { SD } \\
\text { Group I (DM }<5 \text { years) }\end{array}$ & $\begin{array}{c}\text { Mean } \pm \text { SD } \\
\text { Group III (DM }>10 \text { years) }\end{array}$ & S value & \\
\hline Wave I (latency) & $1.7413 \pm 0.2080$ & $1.7267 \pm 0.2460$ & 0.994 & $\mathrm{NS}$ \\
Wave III (latency) & $3.6977 \pm 0.2061$ & $3.6523 \pm 0.2429$ & 0.862 & $\mathrm{NS}$ \\
Wave V (latency) & $5.6107 \pm 0.3006$ & $5.7667 \pm 0.3560$ & 0.256 & $\mathrm{NS}$ \\
Inter peak latency I-III & $1.9563 \pm 0.2394$ & $1.9257 \pm 0.2811$ & 0.975 & $\mathrm{NS}$ \\
Inter peak latency I-V & $3.0607 \pm 0.3220$ & $3.1437 \pm 0.2891$ & 0.723 & $\mathrm{NS}$ \\
Inter peak latency III-V & $1.9130 \pm 0.3545$ & $2.1143 \pm 0.4757$ & 0.240 & $\mathrm{NS}$ \\
\hline
\end{tabular}

\begin{tabular}{|c|c|c|c|c|}
\hline Parameters & $\begin{array}{c}\text { Mean } \pm \text { SD } \\
\text { Group II (DM 5-10 years) }\end{array}$ & $\begin{array}{c}\text { Mean } \pm \text { SD } \\
\text { Group III (DM }>10 \text { years) }\end{array}$ & $P$ value & Significance \\
\hline Wave I (latency) & $1.7430 \pm 0.2438$ & $1.7267 \pm 0.2460$ & 0.992 & NS \\
\hline Wave III (latency) & $3.6690 \pm 0.2121$ & $3.6523 \pm 0.2429$ & 0.992 & NS \\
\hline Wave V (latency) & $5.7133 \pm 0.2804$ & $5.7667 \pm 0.3560$ & 0.922 & NS \\
\hline Inter peak latency I-III & $1.9260 \pm 0.3119$ & $1.9257 \pm 0.2811$ & 1.000 & NS \\
\hline Inter peak latency I-V & $3.0620 \pm 0.3423$ & $3.1437 \pm 0.2891$ & 0.733 & NS \\
\hline Inter peak latency III-V & $2.0443 \pm 0.3501$ & $2.1143 \pm 0.4757$ & 0.913 & NS \\
\hline
\end{tabular}

and $\mathrm{V}$ and inter peak latencies I-III, I-V and III- V in any of the study groups irrespective of the duration of disease.

Our findings are consistent with a study which also showed no change in any of the above parameters in diabetic patients of variable duration of illness ranging from 6 months to 25 years ${ }^{6}$ but do not tally with other researchers. ${ }^{8-16}$

The intergroup comparisons also prove to be statistically insignificant with respect to all parameters showing that duration of diabetes has no significant effect on peripheral or central auditory pathways.

These statistically insignificant changes can be attributed to:

(i) Better controlled diabetic patients in our study groups (group I mean FBS 129.03 mg\%; group II mean FBS $138.06 \mathrm{mg}^{0}$ and group III mean FBS $132.8 \mathrm{mg} \%$ ) (Figure1).

(ii) The study group comprised of patients taken from the OPD of hospital GNDH, Amritsar who were on anti diabetic therapy and hence had better glycaemic control.

(iii) No serious patients with probably poorly controlled blood sugar and/or clinical complications from medical wards were taken in our study.

(iv) The study group comprised of most of the diabetic

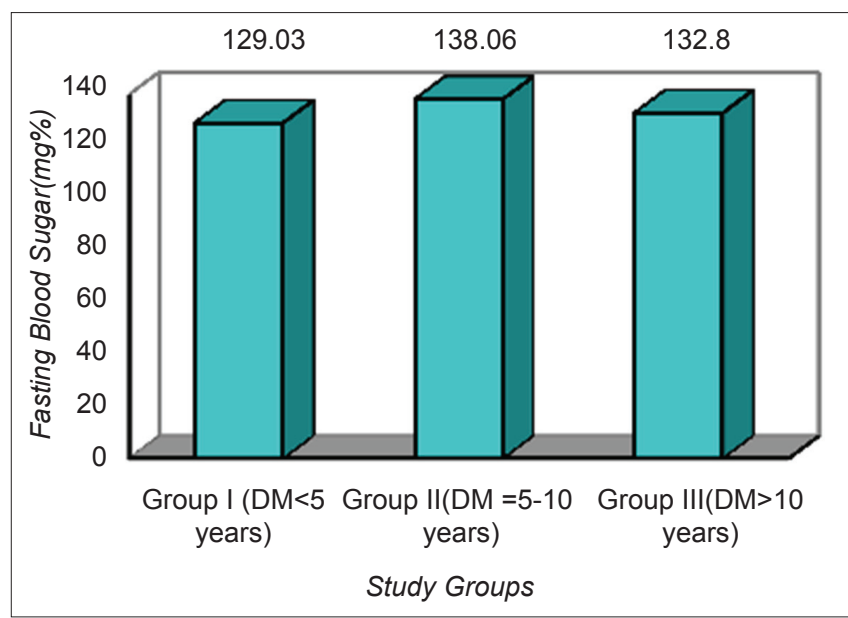

Figure 1: Bar chart showing mean of fasting blood sugar of the study subjects

patients with disease duration of $1-10$ years (60 patients) and only one third of the diabetic patients were with disease duration of more than 10 years.

\section{CONCLUSIONS}

The study can be concluded that no auditory peripheral or central diabetic neuropathy occurred in diabetic patients 
irrespective of duration of the disease, if the patients had a fairly good glycemic control. Probably it might take a longer duration of the disease and/or poorly controlled diabetes mellitus to develop peripheral as well as central auditory diabetic neuropathy.

\section{ACKNOWLEDGEMENT}

I would like to thank the Department of Physiology, Govt Medical College and associated hospital, Amritsar (Punjab), India for having permitted me to carry out the present study in this institution and having allowed me use required institutional facilities; Dr. K.C. Manchanda, Principal, Chintpurni Medical College, Pathankot for his spectacular and absolutely marvelous guidance and encouragement by virtue of which I could do the best; My sincere thanks to my husband Dr. Gagandeep Singh Grover for his data management assistance and To all the subjects who were a part of this study.

\section{REFERENCES}

1. World Health Organization. Report of a WHO/IDF ConsultationDefinition and diagnosis of diabetes mellitus and intermediate hyperglycemia. Printed by the WHO Document Production Services, Geneva, Switzerland 2006; 5.

2. Tuomilehto J, Lindstrom J, Erikson JG, Valls TT, Hamalainen H, Parikke PI, et al. Prevention of Type 2 Diabetes mellitus by changes in lifestyle among subjects with impaired Glucose Tolerance. The New Eng J of Med 2001; 344: 1343-1350.

3. Gupta R, Aslam M, Hasan SA and Siddiqi SS. Type-2 diabetes mellitus and auditory brainstem responses-a hospital based study. Indian J Endocrinol Metab 2010; 14(1): 9-11.

4. Dolphin WH. Auditory Neuropathy and configured hearing loss: The case for two stage screening. The Hearing Review Feb $2004 ; 3(2): 28,30,32$ and 78.

5. Mincewicz MW, Dulska HT, Szajewska BE, Pniewska BZ,
Kochanek K, Pankowska E, et al. Co-existence of abnormalities in the peripheral nervous system and in the auditory and visual evoked potentials in children with type 1 diabetes. Diabetologia Doswiadczalna i Liniczna 2007; 7(1): 44-49.

6. Verma A, Bisht MS and Ahuja GK. Involvement of central nervous system in diabetes mellitus. J Neurol Neurosurg Psychiatry 1984; 47(4): 414-416.

7. Woltman HW and Wilder RM. Diabetes Mellitus. Pathological changes in the spinal cord and peripheral nerves. Arch Intern Med 1929; 44:576-603 In: A Verma, Bisht MS, Ahuja GK. Involvement of central nervous system in diabetes mellitus. J Neurol Neurosurg Psychiatry 1984 April; 47(4): 414-16.

8. Abdulkadiroglu Z, Kaya A, Gonen S and Ithan N. Brainstem Auditory Evoked Potentials in Patients with Type 2 Diabetes Mellitus. Turkish J Endocrinology and Metabolism 1999; 1: 29-32.

9. Mukhopadhyay S, Dhamija RM, Selvamurthy W, Chaturvedi RC, Thakur L, Sapra ML, et al. Auditory evoked response in patients of diabetes mellitus. Ind J Med Res 1992; 96: 81-86.

10. Pan $\mathrm{CH}$, Chen TJ and Chen SS. Brainstem auditory evoked potentials in diabetes mellitus. Zhunguya Yi Xue Za Zhi (Taipei) 1992; 49 (4): 244-252.

11. Ryun CK. Decreased brain function in patients with non-insulin dependent diabetes mellitus. No To Shinkei 1995; 47(6):543-548.

12. Sasso FC, Salvatore T, Tranchino G, Cozzolino D, Causo AA, Persico $\mathrm{M}$, et al. Cochlear dysfunction in type 2 diabetes: A complication independent of neuropathy and acute hyperglycemia. Metabolism 1999; 48(11): 1346-1350.

13. Bayazit $Y$, Yilmaz M, Kepekci $Y$, Mumbuc $S$ and Kanlikama M. Use of the auditory brainstem response testing in the clinical evaluation of the patient with diabetes mellitus. Auris Nasus Larynx 2000; 27(3): 219-222.

14. Toth F, Varkonyi TT, Rovo L, Lengyel C, Legrady P, Jori J, et al. Brainstem auditory evoked potential examination in diabetic patients. Int Tinnitus J 2003; 9(2): 84-86.

15. Al-azzawi LM and Mirza KB. The usefulness of the brainstem auditory evoked potential in the early diagnosis of cranial nerve neuropathy associated with diabetes mellitus. Electromyogr Clin Neurophysiol 2004; 44(7); 387-394.

16. Kiss JG, Toth F, Tamas TV, Laszlo R, Csaba L, Peter L, et al. Brainstem auditory evoked potential (BAEP) examinations in diabetic patients. German Medical Science 2006; Doc 06: 008.

Authors Contribution:

JT - Designed the study, performed the BERA tests, analysed the data and drafted the manuscript; BB - Reviewed the manuscript \& helped in formatting the graphics; GSG - Data management \& Statistical analysis; KCM - Contributed to the study design as a mentor.

Source of Support: Nil, Conflict of Interest: None declared. 